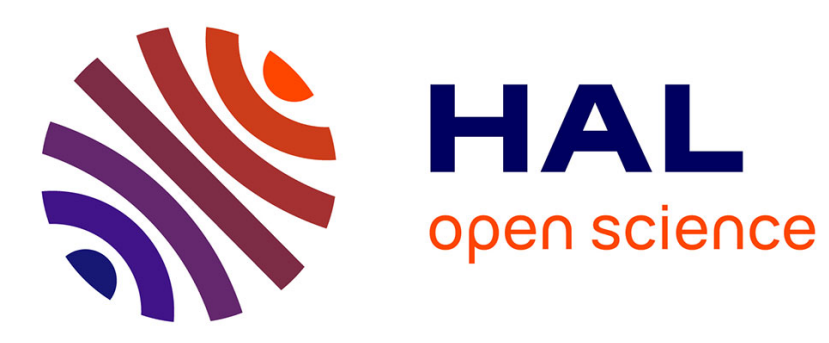

\title{
Corrosion Protection of Mild Steel by a New Phosphonated Pyridines Inhibitor System in $\mathrm{HCl}$ Solution
}

Lilia Tabti, Redha Khelladi, Nadjib Chafai, Alexandre Lecointre, Aline Nonat, Loic Charbonnière, Embarek Bentouhami

\section{To cite this version:}

Lilia Tabti, Redha Khelladi, Nadjib Chafai, Alexandre Lecointre, Aline Nonat, et al.. Corrosion Protection of Mild Steel by a New Phosphonated Pyridines Inhibitor System in HCl Solution. Advanced Engineering Forum, 2020, 36, pp.59-75. 10.4028/www.scientific.net/AEF.36.59 . hal-02965473

\section{HAL Id: hal-02965473 \\ https://hal.science/hal-02965473}

Submitted on 17 May 2021

HAL is a multi-disciplinary open access archive for the deposit and dissemination of scientific research documents, whether they are published or not. The documents may come from teaching and research institutions in France or abroad, or from public or private research centers.
L'archive ouverte pluridisciplinaire HAL, est destinée au dépôt et à la diffusion de documents scientifiques de niveau recherche, publiés ou non, émanant des établissements d'enseignement et de recherche français ou étrangers, des laboratoires publics ou privés. 


\title{
Corrosion protection of mild steel by a new phosphonated Pyridines inhibitor system in $\mathrm{HCl}$ solution
}

Lilia Tabti ${ }^{\mathrm{a}}$, Redha.M. Khelladi ${ }^{\mathrm{a}, \mathrm{b}}$, Nadjib Chafaic ${ }^{\mathrm{c}}$, Alexandre Lecointre ${ }^{\mathrm{d}}$, Aline M. Nonat ${ }^{\mathrm{d}}$ and Loic J. Charbonnière ${ }^{\mathrm{d}}$, Embarek Bentouhami ${ }^{\mathrm{a}^{*}}$.

aLCIMN, Laboratory, Department of Process Engineering, Faculty of Technology, University Ferhat Abbas Setif -1, 19000 Sétif, Algeria

${ }^{b}$ Department of Materials Science, Faculty of Sciences and Technology, Mohamed El Bachir El Ibrahimi University, Bordj-Bou-Arreridj 34030, Algeria

${ }^{c}$ LEMMC, Laboratory, Department of Process Engineering, Faculty of Technology, University Ferhat Abbas Setif -1, 19000 Sétif, Algeria

${ }^{\mathrm{d}}$ LIMAA, IPHC, UMR 7178, University de Starsbourg, ECPM, 25 rue Becquerel, 67087 Strasbourg Cedex 02, France

Corresponding author. E-mail address: labunivstrasbg@gmail.com

\begin{abstract}
The adsorption behavior and inhibition mechanism of (1, 4, 7-Tris [hydrogen (6-methylpyridin2-yl) phosphonate] -1, 4, 7-triazacyclononane) (TPP) on the corrosion of mild steel in $1 \mathrm{M} \mathrm{HCl}$ were investigated by weight loss technique, potentiodynamic polarization, and electrochemical impedance spectroscopy (EIS) methods for different concentrations at $25^{\circ} \mathrm{C}$. The results show that the inhibition efficiency values depend on the amount of immersion times and the concentration. A $90 \%$ efficiency is found at the highest concentration of the studied compound according to weight loss measurements. The adsorption of the investigated inhibitor on the mild steel surface was well supported using an AFM study. For the assignment of the absorption sites, we performed quantum chemical calculations with (DFT) method. The interaction between the inhibitor and iron surface were performed by molecular dynamic (MD) simulations. In this paper, experimental methods and results used to assess the efficiency of the studied compound are presented.
\end{abstract}

Keywords: Phosphonated Pyridines; TPP; Inhibitor; Cyclic voltammetry; DFT calculations. 


\section{Introduction}

Mild steel is widely used as a structural material in automobiles, pipes and chemical industries [1], it undergoes severe corrosion in pickling processes. Hydrochloric and sulfuric acids are widely used for the pickling and the de-scaling of mild steel [2-4]. The use of organic inhibitors is one of the most practical methods and cost-effective choices for protecting metals against corrosion. These organic inhibitors are usually adsorbed on the metal surface via formation of a coordinate covalent bond (chemical adsorption) or the electrostatic interaction between the metal and inhibitor (physical adsorption) [5]. This adsorption produces a uniform film, which isolates the metal surface from the aggressive medium and consequently reduces the corrosion extent [6]. The extent of adsorption depends on the electronic and structural characteristics of the inhibitor, the nature of the surface, the temperature and the pressure of the reaction, the flow velocity as well as the composition of the aggressive environment [7-12]. In general, organic inhibitors containing triple or conjugated double bonds, or aromatic rings in their molecular structures, and those rich in heteroatoms such as sulfur, phosphorus, nitrogen and oxygen were found to be highly electronegative and having electron donating ability; this increases the inhibition efficiency of these compounds in acidic media [13-15]. The implementation of phosphonic acids for the protection of iron and its alloys from corrosion in different media have been the subject of several research works [16-20].

In this paper, we report a new organic inhibitor (1,4,7-tris[hydrogen (6-methylpyridin-2-yl) phosphonate]-1,4,7-triazacyclononane) (TPP) [21]. To our knowledge, TPP has not been considered as a corrosion inhibitor. TPP is chosen as a such mainly based on the following factors: the first is that it contains multiples $\mathrm{N}, \mathrm{P}$ and $\mathrm{O}$ as active centers and a pyridine rings system. Secondly, it has a high solubility in acidic media. The inhibition effect of the TPP on the corrosion of mild steel XC48 in hydrochloric acid using the gravimetric and electrochemical techniques such as potentiodynamic polarization and impedance measurements. On an other hand, the surface state of the mild steel specimens was observed by using atomic force microscopy (AFM). Theoretical studies on electronic and molecular structures were conducted using quantum chemical calculations. Finally, MD simulations studies are used to discuss the adsorption configuration, adsorption energy and explain the mechanism of TPP on iron (110) surface. 


\section{Experimental}

\subsection{Inhibitor}

(1, 4, 7-tris [hydrogen (6-methylpyridin-2-yl) phosphonate]-1, 4, 7-triazacyclononane)(TPP) was synthesized from tacn ( $325 \mathrm{mg}, 2.5 \mathrm{mmol}$ ), and flame-dried $\mathrm{K}_{2} \mathrm{CO}_{3}$ according to literature [21].The chemical structure of the compound is given in Fig. 1.

\subsection{Electrolytic Solution}

The aggressive solution electrolyte grad of $37 \% \mathrm{M} \mathrm{HCl}$ was prepared by dilution with distilled water. The concentrations of the inhibitors TPP was varied from $0.010 \mathrm{mM}$ to $0.075 \mathrm{mM}$.

\subsection{Gravimetric Measurements}

Steel specimens of a dimension of $2 \mathrm{~cm}, 0.7 \mathrm{~cm}$ respectively cleaned with emery papers (having different grades), washed several times with distilled water, acetone then dried in desiccator. The specimens were immersed in $50 \mathrm{~mL}$ of $1 \mathrm{M} \mathrm{HCl}$ for $40 \mathrm{~h}$ in both the absence and the presence of different concentrations of the inhibitor TPP. After an amount of time, the specimens were taken out, washed and weighted. The experiment was performed three times, from gravimetric measurements, $[22,23]$ the corrosion rate $(A)$, the surface coverage $(\theta)$ and inhibition efficiency $\left(\eta_{w} \%\right)$ follows the following equations:

$$
\begin{gathered}
\mathrm{A}=\frac{\Delta \mathrm{W}}{\mathrm{St}}=\frac{\mathrm{W}_{1}-\mathrm{W}_{2}}{\mathrm{~S} \times \mathrm{t}} \\
\theta=\frac{\mathrm{A}_{\text {corr }}^{\circ}-\mathrm{A}_{\text {corr }}}{\mathrm{A}_{\text {corr }}^{\circ}} \\
\eta_{\mathrm{w}} \%=\frac{\mathrm{A}_{\text {corr }}^{\circ}-\mathrm{A}_{\text {corr }}}{\mathrm{A}_{\text {corr }}^{\circ}} \times 100
\end{gathered}
$$

$\mathrm{W}_{1}$ and $\mathrm{W}_{2}$ are respectively the weight of specimens before and after plunge in the examined solution, $\Delta \mathrm{W}$ is the average weight loss $(\mathrm{mg}) . \mathrm{S}$ is the total area of the specimen $\left(\mathrm{cm}^{2}\right), \mathrm{t}$ is the corrosion time $(\mathrm{h}), \mathrm{A}_{\text {corr }}^{\circ}$ and $\mathrm{A}_{\text {corr }}$ are corrosion rates in the absence and presence of the inhibitor, respectively.

\subsection{Electrochemical Measurements}


Electrochemical measurements such as Tafel polarization and electrochemical impedance were conducted on a (PGZ 301 voltalab40 model potentiostat/galvanostat) system connected to a computer. The electrochemical cell consists of an ordinary three-electrode with platinum as a counter electrode, saturated calomel electrode (SCE) as a reference electrode and a mild steel specimen as a working electrode.

The mild steel specimens was exposed to $1 \mathrm{M} \mathrm{HCl}$ corrosive medium in the absence and presence of different concentrations of inhibitor for $1 \mathrm{~h}$ before starting the electrochemical experiments at room temperature and under an open circuit potential (OCP) to reach a steadystate The impedance experiments (EIS) were carried out from Nyquist plot using alternating current (AC) signal of $0.01 \mathrm{~V}$ amplitude for the frequency spectrum from $100 \mathrm{kHz}$ to $0.01 \mathrm{~Hz}$. [24] The values of inhibition efficiency is calculated from charge transfer resistances was obtained using the following equation :

$$
E_{R} \%=\frac{R_{t(i n h)}-R_{t(0)}}{R_{t(i n h)}} \times 100
$$

$R_{t(0))}$ and $R_{t(i n h)}$ are respectively the charge transfer resistances in the absence and presence of the inhibitor.

Tafel plots were registered after the impedance measurement by polarizing the specimen from -700 to $-250(\mathrm{mV} / \mathrm{SCE})$ at a scan rate $2 \mathrm{mV} / \mathrm{s}$. [25, 26] the inhibitory efficiency $E_{P} \%$ and the surface coverage $(\theta)$ are determined by the following equations.

$i_{\text {corr }}^{\circ}$ and $\mathrm{i}_{\text {corr (inh) }}$ correspond to the corrosion current density in the absence and in the presence of inhibitor respectively.

$$
\begin{array}{r}
E_{P} \%=\frac{i_{\text {corr }}^{\circ}-i_{\text {corr }(i n h)}}{i \operatorname{corr}} \times 100 \\
\theta=\frac{i_{\text {corr }}^{\circ}-i_{\text {corr }(\text { inh })}}{i \operatorname{corr}}(6)
\end{array}
$$

\subsection{Surface studies}

The surface morphology of an immersed mild steel specimen in $1 \mathrm{M}$ hydrochloric acid in the absence and presence of inhibitor for $24 \mathrm{~h}$ at $25^{\circ} \mathrm{C}$ were examined by Atomic Force Microscopy (AFM) and recorded using an Asylum Research MFP-3D Classic AFM appliance.

\section{Computational details}




\subsection{Quantum chemical calculations}

The quantum chemical study is performed using density function theory (DFT) method, the Becke three-parameter hybrid functional together and the Lee-Yang-Paar correlation functional (B3LYP) with a 6-31G (d, p) basis set using Gaussian 09 program package was chosen for all the calculations [27-28].

$E_{\mathrm{HOMO}}$ and $E_{\mathrm{LUMO}}$ energies (highest occupied molecular orbital energy and lowest unoccupied molecular orbital energy) are used to calculate all the quantum chemical parameters such as energy gap $\left(\Delta E_{\mathrm{GAP}}\right)$, Hardness $(\eta)$, Softness $(\sigma)$, Electrophilicity index $(\omega)$, Electronegativity $(\chi)$ and fraction of transferred electrons $(\Delta N),[29,30]$ these are calculated according to the following equations respectively.

$$
\begin{aligned}
\eta & =\frac{E_{L U M O}-E_{\text {HOMO }}}{2} \\
\sigma & =\frac{1}{\eta} \\
\omega & =\frac{x^{2}}{2 \eta} \\
\chi & =\frac{-\left(E_{\text {HOMO }}+E_{\text {HOMO }}\right)}{2} \\
\Delta N & =\frac{\chi_{F e}-\chi_{i n h}}{\left[2\left(\eta_{F e}+\eta_{i n h}\right)\right]}
\end{aligned}
$$

Where

$\chi_{F e}$ and $\chi_{i n h}$ : are the absolute electronegativity of Fe and inhibitor molecule respectively. $\eta_{F e}$ and $\eta_{i n h}$ : are the absolute hardness of metal and the inhibitor molecule, respectively. A value of $7.0 \mathrm{eV}$ is used for $\chi_{\mathrm{Fe}}$, while $\eta_{F e}$ is taken as 0 for the calculation of the fraction of transferred electrons [31].

The previous parameters are very important to understand the chemical reactivity of the synthesized compound.

\subsection{Molecular dynamics (MD) simulations}

The simulations were carried with periodic boundary conditions in Materials Studio 7.0 (from Accelrys. Inc) [32] using the force field. Fe (110) surface was chosen for the simulation study. The simulation was carried out in a simulation box with the following dimensions (17.20 $\times 22.93 \times 22.93 \mathrm{~A}^{\circ}$ ). The iron slab, the water slab comprising the investigated inhibitor and a vacuum layer were included in the simulation box. The Fe (100) surface and the molecular structure of the inhibitor in gas phase was first optimized to minimum energy. The temperature was performed at $298 \mathrm{~K}$. NVT set, (constant number of atoms, constant-volume, constant- 
temperature) with a time step of $0.1 \mathrm{fs}$ and simulation time of $50 \mathrm{ps}$ using the COMPASS (condensed phase optimized molecular potentials for atomistic simulation studies).The following equation is used to determine the interaction energy ( $\left.E_{\text {interaction }}\right)$ between the inhibitor and $\mathrm{Fe}(110)$ surface.

$$
\mathrm{E}_{\text {interaction }}=\mathrm{E}_{\text {total }}-\mathrm{E}_{\mathrm{Fe}+\mathrm{H}_{2} \mathrm{O}}-\mathrm{E}_{\mathrm{inh}}
$$

Where $E_{\text {total }}$ is the total energy of mild steel and inhibitor molecules, $E_{\mathrm{Fe}+\mathrm{H}_{2} \mathrm{O}}$ is the energy of iron surface simultaneously with $\mathrm{H}_{2} \mathrm{O}$ molecules and $\mathrm{E}_{\mathrm{inh}}$ represent the total energy inhibitor. The binding energy ( $E_{\text {binding }}$ ) of the inhibitor is the negative value of the interaction energy.

$$
\mathrm{E}_{\text {binding }}=-\mathrm{E}_{\text {interaction }}(13)
$$

\section{Results and discussion}

\subsection{Weight loss results}

The effect of addition of the inhibitor TPP, at different concentrations on the corrosion of mild steel at different immersion times in $1 \mathrm{M} \mathrm{HCl}$ solution was studied by gravimetric measuring. A variation of the inhibition efficiency with concentrations of the inhibitor and various weight loss is shown in Fig. 2 the values deduced for $\theta$ and $\eta_{\mathrm{w}} \%$ are summarized in Table 1.Data in Table 1 shows that the corrosion rate A decreases with the increase in concentration of the inhibitor; consequently, the surface coverage $(\theta)$ and inhibition efficiency $\eta_{\mathrm{w}} \%$ are increased with the increase of the concentration of the inhibitor. Which might be due to the increase adsorption of the inhibitor TPP at the metal / solution interface as their concentration increases [33]. The adsorbed layer from the inhibitor acts as an isolation between the steel and the aggressive medium and hence delays the acidic attack [34, 35]. This type of corrosion inhibitor is increased for a long time however, the inhibitor delays the corrosion at a reduced time.

\subsection{Potentiodynamic polarization curve}

Fig. 3 show the polarization curve for mild steel XC48 immersed in $1 \mathrm{~m} \mathrm{HCl}$ in the absence and presence of different concentrations of inhibitor (TPP). The principal electrochemical parameters of corrosion extracted from polarization such as corrosion potential $\left(\mathrm{E}_{\mathrm{corr}}\right)$, corrosion current density (Icorr), anodic and cathodic Tafel slopes, polarization resistance $\left(R_{P}\right)$, surface coverage $(\theta)$ and inhibition efficiency $\left(E_{P}\right)$ are given in Table 2. It is clear that the values of both cathodic $(\beta c)$ and anodic $(\beta a)$ Tafel constants are strongly changed in the presences of the inhibitor (TPP). This confirms the mixed type inhibition action of the inhibitor (TPP) without changing the anodic dissolution of the metal and the cathodic evolution of hydrogen [36]. 
Furthermore, a slight change occurs in $i_{\text {corr }}$ value with increasing the concentration of the inhibitor, which indicates a delay in the corrosion process [37] add to that, the maximum value of the inhibition efficiency $\left(E_{P}\right) 51.11 \%$ at $0.075 \mathrm{Mm}$. This result indicates that the inhibition activity of the studied molecule (TPP) can be related to adsorption on the metal surface to form a barrier film. This behavior leading therefore to the reduction of the anodic mild steel dissolution and the delay of the cathodic hydrogen reaction.

\subsection{Electrochemical Impedance Spectroscopic Studies}

The Nyquist diagrams obtained of XC48 mild steel in $1 \mathrm{M} \mathrm{HCl}$ in the absence and presence of the inhibitor (TPP) at different concentrations at $25^{\circ} \mathrm{C}$ are show in Fig 4. According to Nyquist diagrams, comparing between the semicircle identical forms of the mild steel shows that the real axis intercept at low frequencies in the presence of inhibitor is bigger than that in the absence of the inhibitor (blank) and increases as the same time as the concentration. This shows that no significant modification in the corrosion mechanism arises as a consequence of the inhibitor presence [38]. In effect, such phenomenon is usually attributed to the frequency dispersal which is assigned to the surface heterogeneity generated from the roughness of the surface and chemical content of mild steel [39]. Furthermore, the addition of an inhibitor increases the values of charge transfer resistance (Rct) is due to the formation of a protective film on the metal/solution interface [40]. And reduces the double layer capacitance $\left(\mathrm{C}_{\mathrm{dl}}\right)$. All this is due to the reduction in local dielectric constant and/or an increment in the thickness of the electrical double layer. The phenomenon proposed that the inhibitor molecule function by the adsorption at the metal surface. Thus, the change in $\mathrm{C}_{\mathrm{dl}}$ is due to the gradual replacement of the water molecule by the adsorption of the inhibitor molecule on the metal surface, decreasing the magnitude of metal dissolution [41].

The value of inhibition efficiency $\left(E_{R} \%\right)$ increases with the concentrations of inhibitor (TPP) and maximum efficiency $(30.67 \%$ ) reached at $0.075 \mathrm{Mm}$ of the inhibitor for $1 \mathrm{~h}$, the results are summarized in Table 3.

In general, the efficiency of an organic substance as an inhibitor for metallic corrosion depend on the structure and the concentration of the inhibitor, the nature of the metal and other experimental conditions, such as the temperature of the medium [20,42].

\subsection{Atomic force microscopy (AFM) studies}

Fig. 5 represents the AFM surface morphology of the mild steel immersed in $1 \mathrm{M} \mathrm{HCl}$ for $24 \mathrm{~h}$ solutions without and with the optimum concentration of the inhibitor was taken in $2 \mathrm{D}$ and $3 \mathrm{D}$ 
to confirm the formation of a protective layer on the mild steel surface. It can be seen from the AFM micrograph of the mild steel (Fig.5a) in the absence of the inhibitor (Fig. 5b) that the surface showed a very irregular morphology with highly corroded and damaged surface due to corrosive attack of acid. On the other hand, in the presence of optimum concentration $0,075 \mathrm{mM}$ of the inhibitor (Fig. 5c), the corrosion product on the corrosion product on the surface of the metal was diminished and the surface became smoother.

The calculated surface roughness (given in table 4) of mild steel in $1 \mathrm{M} \mathrm{HCl}$ without the inhibitor $(187.456 \mathrm{~nm})$ was higher than that of the mild steel $(7.310 \mathrm{~nm})$. But in the presence of the inhibitor the value roughness was reduced to $(47.051 \mathrm{~nm})$ and this reduction, which confirms the formation protective surface layer by the inhibitor and corrosion rate is reduced.

\subsection{Computational study}

\subsubsection{Quantum chemical calculations}

The optimized molecular structure of the inhibitor (TPP) calculated using B3LYP/6- 31G (d, p) method of the most stable form is shown in Fig. 6. The literature shows that the adsorption of the inhibitor on the metal surface can be placed on the basis of donor-acceptor interactions between the $\pi$-electrons of the heterocyclic structure and the vacant d-orbital of the metal surface atoms. The electron acceptor distribution in the lowest unoccupied molecular orbital (LUMO) and the electron donor distribution in the highest occupied molecular orbital (HOMO) are shown in Fig.7.

Lately, quantum chemical calculations were largely used in corrosion inhibition investigations. Especially since they seem to be effective in the study of corrosion inhibition mechanisms of organic compounds $[43,44]$, the effectiveness of an inhibitor can be attached to some quantum chemical parameters such as: energy gap $\left(\Delta \mathrm{E}_{\mathrm{GAP}}=\mathrm{E}_{\mathrm{LUMO}}-\mathrm{E}_{\mathrm{HOMO}}\right)$, the dipole moment $(\mu)$, and Mullikan charges on the backbone atoms which were determined by optimization and they can be related to the metal-inhibitor interactions [45]. The obtained values of the quantum chemical parameters for the investigated inhibitor are listed in Table 5.

From Fig. 7 and Table 5, we can notice that the $\mathrm{E}_{\mathrm{HOMO}}$ is found to reside on the pyridine ring and heteroatoms for the studied compound and the higher value of $\mathrm{E}_{\text {HOMO }}$ indicates the tendency of electron transfer to an appropriate acceptor molecule which facilitates the adsorption of the inhibitor on the metal surface by influencing the electron transfer processes through the adsorbed layer $[46,47]$. Moreover, the lower value of $E_{\text {LUMO, }}$ the easier is the acceptance of electrons from the $\mathrm{d}$ orbital of the metal [48]. On an other hand, the value of $\Delta \mathrm{E}_{\mathrm{GAP}}$ provides a measure for the stability of the formed complex on the metal surface. In principle, a decrease 
in the energy gap leads to easier polarization of the molecule, greater adsorption on the surface and improved the inhibition efficiency of the inhibitor $[49,50]$.

Several researchers have shown that the dipole moment is resultant to the polarity of an inhibitor and the elevated values of $\mu$ are answerable for great inhibition effectiveness [51, 52]. Table 5 shows that the high value of the dipole moment acquired and the low energy gap causes electron transfer from the molecule to the surface and this takes place during adsorption on the mild steel surface.

$\Delta N$ means that the fraction of transferred electrons from the inhibitor molecule to the mild steel surface and indicates the capability of the inhibitor to donate electrons. The literature shows that a value of $\Delta \mathrm{N}<3.6$, the inhibition effectiveness raises the electrons donating capability at the metal surface [53].

\subsubsection{Molecular electrostatic potential surfaces (MEP)}

The molecular electrostatic potential map (MEP) which demonstrates molecular size, shape as well as charge distribution of the compound to find the active sites responsible for electrophilic and nucleophilic attacks is a powerful tool in the study of interaction of a molecular system with its surroundings. Furthermore, MEP is related to the electronic density. Fig. 8 illustrates the map of the studied inhibitor represented by different colors. The yellow zones of the MEP represent the negative potential related to electrophilic reactivity, while the blue color represents the positive zones related to nucleophilic reactivity.

The region of the phosphonate groups is highly negatively charged (fig.8, table.6) correspond of atom oxygen obtained with Milliken charge ware located on O32, $\mathrm{O} 33, \mathrm{O} 34, \mathrm{O} 36, \mathrm{O} 37, \mathrm{O} 38, \mathrm{O} 40, \mathrm{O} 41, \mathrm{O} 42$, whereas positive potentials are presented at hydrogen atoms. It is clear from the Table. 6 that the nitrogen atom and some carbon of TACN and pyridine of the inhibitor have negative charges, which are probably the active adsorptive sites.

\subsubsection{MD simulations}

The objective of this study is to find the nearer inhibitor molecule to Fe (110) surface. MD simulations were performed on a system comprising TPP molecule and iron surface in a vacuum slab (Fig. 9). From Fig. 9 we can see that the investigated inhibitor is adsorbed nearly parallel to the metal surface, this adsorption on the Fe (110) surface through oxygen, nitrogen and the pyridine rings present in the inhibitor, which leads to the formation of coordinate bonds (chemical interactions) [54]. The calculated values of the interaction and the binding energies are given in Table 7 . 


\section{Conclusion}

From the above results, we can deduce the following conclusions:

$\checkmark$ The new compound TPP treated as a corrosion inhibitor in $1 \mathrm{M} \mathrm{HCl}$ in the mild steel.

$\checkmark$ The gravimetric measurements showed that the inhibition efficiency increases with the inhibitor at different concentration and immersion times.

$\checkmark$ The potentiodynamic polarization showed that the TPP acts as a mixed type inhibitor. EIS results reveal that the presence of the inhibitor molecules increases in the charge transfer resistance values while reducing the double layer capacitance values.

$\checkmark$ The atomic force microscopy (AFM) showed that the surface roughness decreases in the presence of TPP, due to establishment of a protective surface

$\checkmark$ The quantum chemical study shows that the nitrogen and oxygen atoms in the inhibitor molecule are the main active sites that result in adsorption of TPP on the mild steel surface.

$\checkmark$ The binding energy calculated by the MD method was also in accordance with the experimental results, and the binding energy of TPP was the highest.

\section{References}

[1] M. Shymala, P.K. Kasthuri, The inhibitory action of the extracts of Adathodavasica, Ecliptaalba, and Centellaasiatica on the corrosion of mild steel in hydrochloric acid medium: a comparative study, Int. J. Corros. (2012) 1-13.

[2] L.R. Chauhan, G. Gunasekauran, Corrosion inhibition of mild steel by plant extract in dilute $\mathrm{HCl}$ medium, Corros. Sci. 49 (2007) 1143-1161. 
[3] S.S. Shivakumar, K.N.S. Mohana, Ziziphusmauritiana leaves extracts as corrosion inhibitor for mild steel in H2SO4 and HCl solutions, Eur. J. Chem. 3 (2012) 426-432.

[4] M.A. Quraishi, A. Singh, V.K. Singh, D.K. Yadav, A.K. Singh, Green approach to corrosion inhibition of mild steel in hydrochloric acid and sulphuric acid solutions by the extract of Murrayakoenigii leaves, Mater. Chem. Phys. 122 (2010) 114-122.

[5] G. Avci, Inhibitor effect of N,N-methylenediacrylamide on corrosion behavior of mild steel in $0.5 \mathrm{M} \mathrm{HCl}$, Mater. Chem. Phys. 112 (2008) 234-238.

[6] E.S. Meresht, T.S. Farahani, J. Neshati, 2-Butyne-1,4-diol as anovel corrosion inhibitor for API X65 steel pipeline in carbon-ate/bicarbonate solution, Corros. Sci. 54 (2012) 36-44.

[7] M. Heydari, M. Javidi, Corrosion inhibition and adsorption behaviour of an amidoimidazoline derivative on API 5L X52 steel in CO2-saturated solution and synergistic effect of iodide ions, Corros. Sci. 61 (2012) 148-155.

[8] X. Jiang, Y.G. Zheng, W. Ke, Effect of flow velocity and entrained sand on inhibition performances of two inhibitors for $\mathrm{CO} 2$ corrosion of $\mathrm{N} 80$ steel in $3 \% \mathrm{NaCl}$ solution, Corros. Sci. 47 (2005) 2636-2658.

[9] A.Garnica-Rodriguez, J. Genesca, J. Mendoza-Flores, R. Duran-Romero, Electrochemical evaluation of aminotriazole corrosion inhibitor under flow conditions, J. Appl. Electrochem. 39 (2009) 1809-1819.

[10] P.C. Okafor, X. Liu, Y.G. Zheng, Corrosion inhibition of mild steel by ethylamino imidazoline derivative in CO2-saturated solution, Corros. Sci. 51 (2009) 761- 768.

[11] A.A. Mazhar, W.A. Badaway, M.M. Abou-Romia. Impedance studies of corrosion resistance of aluminium in chloride media. Surf.Coat.Techol. 29 (1986) 335-345.

[12] A. Zarrouk, B. Hammouti, H. Zarrok, R. Salghi, A. Dafali, Lh.Bazzi, L. Bammou, S.S. Al-Deyab, Electrochemical impedancespectroscopy and weight loss study for new pyridazine derivativeas inhibitor for copper in nitric acid, Der Pharm. Chem. 4 (2012)337-346.

[13] M. Gopiraman, N. Selvakumaran, D. Kesavan, R. Karvembu, Adsorption and corrosion inhibition behaviour of $\mathrm{N}$-(phenylcarbamothioyl)benzamide on mild steel in acidic medium, Prog. Org. Coat. 73 (2012) 104-111.

[14] H. Hamani, T. Douadi, M. Al-Noaimi, S. Issaadi, D. Daoud, S. Chafaa. Electrochemical and quantum chemical studies of some azomethine compounds as corrosion inhibitors for mild steel in $1 \mathrm{M}$ hydrochloric acid.CorrosSci 88 (2014) 234-245 .

[15] S.L. Granese, B.M. Rosales, C. Oviedo, J.O. Zerbino. The inhibition action of heterocyclic nitrogen organic compounds on $\mathrm{Fe}$ and steel in $\mathrm{HCl}$ media.Corrosion Sci 33(1992)1439-53.

[16] El Ashry E , El Nemr A, Essawy S , Ragab S . Corrosion inhibitors part V: QSAR of benzimidazole and 2-substituted derivatives as corrosion inhibitors by using the quantum chemical parameters. Prog Org Coat 61 (2008)11-20.

[17] M. Djenane, S. Chafaa, N. Chafai, R. Kerkour, A. Hellal. Synthesis, spectral properties and corrosion inhibition efficiency of new ethyl hydrogen [(methoxyphenyl)(methylamino) methyl] phosphonate derivatives: Experimental and theoretical investigation. Journal of Molecular Structure. 1175 (2018) 398-413.

[18] M.R. Laamari, J. Benzakour, F. Berrekhis, A. Derja, D. Villemin. Adsorption and corrosion inhibition of mild steel in hydrochloric acid medium by hexamethylenediamine tetra(methylene phosphonic acid) Arabian Journal of Chemistry 9 (2016) 245-251

[19] H.Amar,J.Benzakour,A.Derja,D.Villemin,B.Moreau,T.Braisaz.Piperidin-1-ylphosphonic acid and (4-phosphono-piperazin-1-yl) phosphonic acid: A new class of iron corrosion inhibitors in sodium chloride 3\% media. Applied Surface Science 252 (2006) 6162-6172 
[20] K. Benbouguerra, S. Chafaa, N. Chafai, M. Mehri, O. Moumeni, A. Hellal. Synthesis, spectroscopic characterization and a comparative study of the corrosion inhibitive efficiency of an $\alpha$-aminophosphonate and Schiff base derivatives: Experimental and theoretical investigations. Journal of Molecular Structure. 1157 (2018) 165-176.

[21] M.R. Laamari, J. Benzakour, F. Berrekhis, M. Bakasse, D. Villemin. Investigation of the effect of piperidin-1-ylphosphonic acid on corrosion of iron in sulfuric acid.Arabian Journal of Chemistry 9 (2016) 1218-1224

[22] J.Salaam,L.Tabti,S.Bahamyirou,A.Lecointre,O.H.Alba,O.Jeannin,F.Camerel,S. Cianférani,E.Bentouhami, A.M. Nonat,and L.J. Charbonnière. Formation of Monoand Polynuclear Luminescent Lanthanide Complexes based on the Coordination of PreorganizedPhosphonated Pyridines Inorg. Chem. 57 (2018) 6095-6106

[23] A. A. Farag, M.R. Noor El-Din, The adsorption and corrosion inhibition of some nonionic surfactants on API X65 steel surface in hydrochloric acid, Corros. Sci. 64 (2012) 174-183.

[24] D.K. Yadav, M.A. Quraishi, B. Maiti, Inhibition effect of some benzylidenes on mild steel in $1 \mathrm{M} \mathrm{HCl}$ : an experimental and theoretical correlation. Corros. Sci. 55 (2012) 254-266.

[25] Z Tao,S Zhang, WLi, B Hou.Corrosion inhibition of mild steel in acidic solution by some oxo-triazole derivatives.Corros.Sci.51 (2009) 2588-95.

[26] M Shahin, S Bilgic, H Yilmaz. The inhibition effects of some cyclic nitrogen compoundson the corrosion of the steel in $\mathrm{NaCl}$ medium. Appl. Surf. Sci. 195(2003) $1-7$.

[27] A.D.Becke, A new mixing of Hartree-Fock and local density-functional theories. J.Chem.Phys 98 (1993)1372-1377.

[28] H.B. Schlegel, G.E. Scuseria, M.A. Robb, J.R. Cheeseman, G. Scalmani, V. Barone, B. Mennucci, G.A. Petersson, H. Nakatsuji, M. Caricato, X. Li, H.P. Hratchian, A.F. Izmaylov, J. Bloino, G. Zheng, J.L. Sonnenberg, M. Hada, M. Ehara, K. Toyota, R. Fukuda, J. Hasegawa, M. Ishida, T. Nakajima, Y. Honda, O. Kitao, H. Nakai, T. Vreven, J.A. Montgomery Jr., J.E. Peralta, F. Ogliaro, M. Bearpark, J.J. Heyd, E. Brothers, K.N. Kudin, V.N. Staroverov, R. Kobayashi, J. Normand, K. Raghavachari, A. Rendell, J.C. Burant, S.S. Iyengar, J. Tomasi, M. Cossi, N. Rega, J.M. Millam, M. Klene, J.E. Knox, J.B. Cross, V. Bakken, C. Adamo, J. Jaramillo, R. Gomperts, R.E. Stratmann, O. Yazyev, A.J. Austin, R. Cammi, C. Pomelli, J.W. Ochterski, R.L. Martin, K. Morokuma, V.G. Zakrzewski, G.A. Voth, P. Salvador, J.J. Dannenberg, S. Dapprich, A.D. Daniels, O. Farkas, J.B. Foresman, J.V. Ortiz, J. Cioslowski, D.J. Fox, Gaussian 09, Revision A.02, Gaussian, Inc., Wallingford, CT, 2009.

[29] B. Ramaganthan, M. Gopiraman, L.O. Olasunkanmi, M.M. Kabanda, S. Yesudass, I. Bahadur, A.S. Adekunle, I.B. Obot, E.E. Ebenso, Synthesized photo-cross-linking chalcones as novel corrosion inhibitors for mild steel in acidic medium: experimental, quantum chemical and Monte Carlo simulation studies, RSC Adv. 5 (2015) 7667576688.

[30] E.E. Oguzie, C.B. Adindu, C.K. Enenebeaku, C.E. Ogukwe,M.A. Chidiebere, K.L. Oguzie, Natural products for materials protection: mechanism of corrosion inhibition of mild steel by acid extracts of Piper guineense, J. Phys. Chem. C 116 (2012) 1360313615.

[31] V.S. Sastri, J.R. Perumareddi . Molecular orbital theoretical studies of some or- ganic corrosion inhibitors.Corrosion 53 (1997) 617-629.

[32] Materials studio, 7.0 San Diego, CA: Accelrys Inc.; 2013. 
[33] I.B. Obot, N.O. Obi-Egbedi. Anti-corrosive properties of xanthone on mild steel corrosion in sulphuric acid: experimental and theoretical investigations, Curr. Appl. Phys. 11 (2011) 382-392.

[34] A.K. Maayta, N.A.F. Al-Rawashdeh. Inhibition of acidic corrosion of pure aluminum by some organic compounds.Corros. Sci. 46 (2004) 1129-1140

[35] J. Aljourani, K. Raeissi, M.A. Golozar. Benzimidazole and its derivatives as corrosion inhibitors for mild steel in $1 \mathrm{M} \mathrm{HCl}$ solution. Corros. Sci. 51 (2009) 1836-1843

[36] C.Cao. On Electrochemical technique for interface inhibitor research.Corrs.Sci.38 (1996) 2073-2082.

[37] I.B .Obot, N.O. Obi-Egbedi, N.W. Odozi. Acenaphtho[1,2-b] quinoxaline as a novel corrosion inhibitor for mild steel in 0.5M H $\mathrm{SO}_{4}$. Corros. Sci. 52(2010) 923-926.

[38] N.Labjar, M.Lebrini, F.Bentiss, N.E.Chihib, S.El Hadjjaji, C.Jama. Corrosion inhibition of mild steel and antibacterial proprieties of aminotris(methyl nephosnic) acid,Mater.Chem.Phys.119 (2010) 330-336.

[39] F.Bentiss, M. Lebrini, M. Lagrenee, Thermodynamic characterization of metal dissolution and inhibitor adsorption processes in mild steel/2,5-bis(n-thienyl)- 1,3,4thiadiazoles/hydrochloric acid system, Corros. Sci. 47 (2005) 2915-2931.

[40] W. Li, Q. He, S. Zhang, C. Pei, B. Hou, Some new triazole derivatives as inhibitors for mild steel corrosion in acidic medium J. Appl. Electrochem. 38 (2008) 289-295.

[41] C.M. Goulart, A. Esteves-Souza, C.A. Martinez-Huitle, C.J.F. Rodrigues, M.A.M. Maciel, A. Echevarria, Experimental and theoretical evaluation of semicarbazones and thiosemicarbazones as organic corrosion inhibitors, Corros. Sci. 67 (2013) 281-291.

[42] R. Hasanov, M. Sadıkoğlu, S. Bilgic, Electrochemical and quantum chemical studies of some Schiff bases on the corrosion of steel in $\mathrm{H}_{2} \mathrm{SO}_{4}$ solution, Appl. Surf. Sci. 253 (2007) 3913-3921.

[43] G. Gece .The use of quantum chemical methods in corrosion inhibitor studies.CorrosSci 50 (2008) 2981-2992.

[44] E. Jamalizadeh, S.M.A. Hosseini, A.H.Jafari. Quantum chemical studies on corrosion inhibition of some lactones on mild steel in acid media.CorrosSci 51 (2009) 14281435.

[45] K. F. Khaled .Electrochemical investigation and modeling of corrosion inhibition of aluminum in molar nitric acid using some sulphur-containing amines.CorrosSci 52 (2010) 2905-2916.

[46] I. Lukovits, K. Pálfi, I. Bakó, E. Kálmán. LKP model of the inhibition mechanism of thiourea compounds. Corrosion 53 (1997) 915-919.

[47] A.Y. Musa, A.A.H. Kadhum, A.B. Mohamad, A.A. Rahoma, H. Mesmari, Electrochemical and quantum chemical calculations on 4,4- dimethyloxazolidine-2thione as inhibitor for mild steel corrosion in hydrochloric acid, J. Mol. Struct. 969 (2010) 233-237.

[48] M. Finšgar, A. Lesar, A. Kokalj, I. Milošev, A comparative electrochemical and quantum chemical calculation study of BTAH and BTAOH as copper corrosion inhibitors in near neutral chloride solution, Electrochim. Acta 53 (28) (2008) 82878297.

[49] D. Zhang, Z. An, Q. Pan, L. Gao, G. Zhou, Comparative study of bispiperidiniummethyl-urea and mono-piperidiniummethyl-urea as volatile corrosion inhibitors for mild steel, Corrosion Sci. 48 (2006) 1437-1448.

[50] A.S. Fouda, A.S. Ellithy. Inhibition effect of 4-phenylthiazole derivatives on corrosion of 304L stainless steel in $\mathrm{HCl}$ solution.Corros. Sci. 51 (2009) 868-875.

[51] R.M. Issa, M.K. Awad, F.M. Atlam, Quantum chemical studies on the inhibition of corrosion of copper surface by substituted uracils, Appl. Surf. Sci. 255 (2008) 24332441. 
[52] M. Lashkari, M.R. Arshadi, DFT studies of pyridine corrosion inhibitors in electrical double layer: solvent, substrate, and electric field effects, Chem.Phys. 299 (2004) 131-137.

[53] I. Lukovits, E. Kálmán, F. Zucchi, Corrosion inhibitors-correlation between electronic structure and efficiency, Corrosion 57 (2001) 3-8.

[54] N. Chafai, S. Chafaa, K. Benbouguerra, D. Daoud, A. Hellal, M. Mehri. Synthesis, characterization and the inhibition activity of a new aaminophosphonic derivative on the corrosion of XC48 mild steel in $0.5 \mathrm{M} \mathrm{H}_{2} \mathrm{SO}_{4}$ : Experimental and theoretical studies..Journal of the Taiwan Institute of Chemical Engineers 70 (2017) 331-344

\section{Table Captions}

Table 1 
Gravimetric results of mild steel at different immersion times in $1 \mathrm{M} \mathrm{HCl}$ without and with the addition of the inhibitor at $25^{\circ} \mathrm{C}$.

\section{Table 2}

Electrochemical corrosion parameters of mild steel in the absence and presence of various concentrations of inhibitor (TPP) in $1 \mathrm{M} \mathrm{HCl}$.

\section{Table 3}

Electrochemical impedance parameters for mild steel in $1 \mathrm{M} \mathrm{HCl}$ containing different concentrations of inhibitor (TPP).

\section{Table 4}

Table 4 AFM data obtained of mild steel in $1 \mathrm{M} \mathrm{HCl}$ immersed in inhibited and uninhibited at $298 \mathrm{~K}$.

\section{Table 5}

Calculated quantum chemical parameters of the investigated inhibitor (TPP).

\section{Table 6}

Obtained Mullikan atomic charges of the inhibitor (TPP).

\section{Table 7}

Interaction and binding energies between the inhibitor molecules (TPP) and Fe (100) surface.

\section{Figure Captions}


Figure 1. The chemical structure of the inhibitor TPP.

Figure 2. Variation of the corrosion rate $(\boldsymbol{\square})$ and the inhibition efficiency $(\boldsymbol{\Delta})$ with various concentration of inhibitor (TPP).

Figure 3. Tafel polarization curves for the corrosion of mild steel $\mathrm{XC} 48$ in $1 \mathrm{M} \mathrm{HCl}$ with and without various concentrations of the inhibitor at $25^{\circ} \mathrm{C}$.

Figure 4. Nyquist plots for the mild steel XC48 in $1 \mathrm{M} \mathrm{HCl}$ solution with different concentrations of the inhibitor (TPP).

Figure 5. AFM images 2D (on the Left) and 3D (on the Right), mild steel surface ; (XC48) polished mild steel, mild steel in $1 \mathrm{M} \mathrm{HCl}$, mild steel after immersion in $1 \mathrm{M} \mathrm{HCl}$ in presence of $0.075 \mathrm{~m} \mathrm{M}$ of inhibitor(TPP).

Figure 6. Optimized molecular structure of inhibitor TPP.

Figure 7. The frontier molecular orbital density distributions for inhibitor (TPP).

Figure 8. Molecular electrostatic potential of inhibitor (TPP).

Figure 9. Equilibrium configuration of the adsorbed molecule on the Fe (110) surface vacuum slab: (a) top view, (b): side view. 
Gravimetric results of mild steel at different immersion times in $1 \mathrm{M} \mathrm{HCl}$ without and with the addition of the inhibitor at $25^{\circ} \mathrm{C}\left(\mathrm{S}=3.14 \mathrm{~cm}^{2}\right)$.

\begin{tabular}{|c|c|c|c|c|c|}
\hline \multicolumn{2}{|c|}{$\begin{array}{l}\text { Concentration / time } \\
\quad(\mathrm{mM})\end{array}$} & $\begin{array}{l}\Delta \mathrm{m} \\
(\mathrm{mg})\end{array}$ & $\begin{array}{c}\mathrm{A} \\
\left(\mathrm{mg} / \mathrm{cm}^{2} \mathrm{~h}\right)\end{array}$ & $\theta$ & $\begin{array}{l}\eta_{\mathrm{w}} \\
(\%)\end{array}$ \\
\hline Blanc & & 476.3 & 15.16 & -- & -- \\
\hline 0.010 & & 288.1 & 9.17 & 0.40 & 40 \\
\hline 0.025 & 10 Hours & 240.7 & 7.66 & 0.48 & 48 \\
\hline 0.050 & & 190.6 & 6.07 & 0.60 & 60 \\
\hline 0.075 & & 150.2 & 4.78 & 0.68 & 68 \\
\hline Blanc & & 476.3 & 7.58 & -- & -- \\
\hline 0.010 & & 252.8 & 4.03 & 0.47 & 47 \\
\hline 0.025 & 20 Hours & 211.3 & 3.36 & 0.55 & 55 \\
\hline 0.050 & & 145.2 & 2.31 & 0.70 & 70 \\
\hline 0.075 & & 101.5 & 1.62 & 0.78 & 78 \\
\hline Blanc & & 476.3 & 5.04 & -- & -- \\
\hline 0.010 & & 232.5 & 2.46 & 0.51 & 51 \\
\hline 0.025 & 30 Hours & 190.8 & 2.01 & 0.60 & 60 \\
\hline 0.050 & & 120.5 & 1.27 & 0.75 & 75 \\
\hline 0.075 & & 082.6 & 0.87 & 0.83 & 83 \\
\hline Blanc & & 476.3 & 3.792 & -- & -- \\
\hline 0.010 & & 220.0 & 1.751 & 0.54 & 54 \\
\hline 0.025 & 40 Hours & 157.1 & 1.250 & 0.67 & 67 \\
\hline 0.050 & & 095.1 & 0.757 & 0.80 & 80 \\
\hline 0.075 & & 051.9 & 0.413 & 0.90 & 90 \\
\hline
\end{tabular}




\section{Table 2}

Electrochemical corrosion parameters of mild steel in the absence and presence of various concentrations of inhibitor (TPP) in $1 \mathrm{M} \mathrm{HCl} 25^{\circ} \mathrm{C} / 1 \mathrm{~h}$.

\begin{tabular}{lccccccc}
\hline $\begin{array}{c}\text { Concentration } \\
(\mathrm{mM})\end{array}$ & $\begin{array}{c}-\mathrm{E}_{\text {corr }} \\
(\mathrm{mV} / \mathrm{ECS})\end{array}$ & $\begin{array}{c}-\beta_{\mathrm{c}} \\
(\mathrm{mV} / \mathrm{dec})\end{array}$ & $\begin{array}{c}\beta_{\mathrm{a}} \\
(\mathrm{mV} / \mathrm{dec})\end{array}$ & $\begin{array}{c}\mathrm{i}_{\text {corr }} \\
\left(\mu \mathrm{A} / \mathrm{cm}^{2}\right)\end{array}$ & $\begin{array}{c}\mathrm{R}_{\mathrm{p}} \\
\left(\Omega \mathrm{cm}^{2}\right)\end{array}$ & $\begin{array}{c}E_{P} \\
(\%)\end{array}$ & $\theta$ \\
\hline Blanc & 463 & 150.5 & 119.1 & 0.090 & 246.6 & -- & - \\
0.010 & 458 & 129.3 & 104.2 & 0.074 & 287.2 & 17.77 & 0.17 \\
0.025 & 454 & 114.4 & 139.6 & 0.067 & 319.5 & 25.55 & 0.25 \\
0.050 & 451 & 123.2 & 102.2 & 0.062 & 328.4 & 31.11 & 0.31 \\
0.075 & 446 & 102.6 & 112.5 & 0.044 & 338.1 & 51.11 & 0.51 \\
\hline
\end{tabular}


Table 3

Electrochemical impedance parameters for mild steel in $1 \mathrm{M} \mathrm{HCl}$ containing different concentrations of inhibitor (TPP) $25^{\circ} \mathrm{C} / 1 \mathrm{~h}$.

\begin{tabular}{lcccc}
\hline $\begin{array}{c}\text { Concentration } \\
(\mathrm{mM})\end{array}$ & $\begin{array}{c}\mathrm{R}_{\mathrm{s}} \\
\left(\Omega \mathrm{cm}^{2}\right)\end{array}$ & $\begin{array}{c}\mathrm{R}_{\mathrm{ct}} \\
\left(\Omega \mathrm{cm}^{2}\right)\end{array}$ & $\begin{array}{c}\mathrm{C}_{\mathrm{dl}} \\
\left(\mu \mathrm{F} / \mathrm{cm}^{-2}\right)\end{array}$ & $\begin{array}{c}E_{R} \\
(\%)\end{array}$ \\
\hline Blanc & 2.54 & 196.4 & 293.2 & -- \\
0.010 & 2.63 & 244.5 & 172.0 & 19.67 \\
0.025 & 3.02 & 256.1 & 153.5 & 23.31 \\
0.050 & 2.68 & 264.6 & 151.5 & 25.77 \\
0.075 & 3.10 & 283.3 & 95.4 & 30.67 \\
\hline
\end{tabular}


Table 4

AFM data obtained of mild steel in $1 \mathrm{M} \mathrm{HCl}$ immersed in inhibited and uninhibited at $298 \mathrm{~K}$.

\begin{tabular}{lllc}
\hline AFM & Mild steel & $1 \mathrm{M} \mathrm{HCl}$ & 0,075 \\
data & & Blank & $\mathrm{mM}$ \\
\hline roughness $(\mathrm{nm})$ & 7.310 & 187.456 & 47.051 \\
\hline
\end{tabular}




\section{Table 5}

Calculated quantum chemical parameters of the investigated inhibitor (TPP).

\begin{tabular}{ll}
\hline Quantum chemical parameter & InhibitorTPP \\
\hline $\mathrm{E}_{\mathrm{Tot}}(\mathrm{eV})$ & -80660.7952822213 \\
$\mathrm{E}_{\mathrm{HOMO}}(\mathrm{eV})$ & -8.62955 \\
$\mathrm{E}_{\mathrm{LUMO}}(\mathrm{eV})$ & -5.3516653 \\
$\Delta \mathrm{E}_{\mathrm{GAP}}(\mathrm{eV})$ & 3.2778847 \\
$\mu(\mathrm{Debye})$ & 6.4605 \\
$\eta(\mathrm{eV})$ & 1.6389424 \\
$\Sigma$ & 0.6101495 \\
$\chi(\mathrm{eV})$ & 6.9906077 \\
$\Omega$ & 14.909856 \\
$\Delta \mathrm{N}$ & 0.002865354 \\
\hline
\end{tabular}




\section{Table 6}

Obtained Mullikan atomic charges of the inhibitor (TPP).

\begin{tabular}{|c|c|c|c|c|c|}
\hline Atom & Mulliken Charge & Atom & Mulliken Charge & Atom & $\begin{array}{l}\text { Mulliken } \\
\text { Charge }\end{array}$ \\
\hline $\mathrm{C} 1$ & -0.4062436 & N26 & -0.5924872 & H51 & 0.2832758 \\
\hline $\mathrm{C} 2$ & -0.4408006 & $\mathrm{C} 27$ & 0.2390047 & H52 & 0.2668431 \\
\hline $\mathrm{C} 3$ & -0.4636576 & $\mathrm{C} 28$ & -0.3732743 & H53 & 0.2767447 \\
\hline N4 & -0.4827192 & C29 & -0.3896199 & H54 & 0.3216647 \\
\hline $\mathrm{C} 5$ & -0.3685648 & C30 & -0.2408759 & H55 & 0.2925512 \\
\hline N6 & -0.4010391 & P31 & 1.7598520 & H56 & 0.3009605 \\
\hline N7 & -0.4406184 & $\mathrm{O} 32$ & -0.9412391 & H57 & 0.2999258 \\
\hline $\mathrm{C} 8$ & -0.3692009 & $\mathrm{O} 33$ & -0.8002294 & H58 & 0.3022151 \\
\hline C9 & -0.5867098 & $\mathrm{O} 34$ & -0.7998068 & H59 & 0.2819155 \\
\hline $\mathrm{C} 10$ & -0.4273687 & P35 & 1.7669255 & H60 & 0.2881563 \\
\hline C11 & 0.4210028 & $\mathrm{O} 36$ & -0.9464684 & H61 & 0.2742818 \\
\hline $\mathrm{C} 12$ & -0.4881902 & $\mathrm{O} 37$ & -0.8034906 & H62 & 0.2833459 \\
\hline $\mathrm{C} 13$ & 0.3961610 & $\mathrm{O} 38$ & -0.8048440 & H63 & 0.2806907 \\
\hline $\mathrm{C} 14$ & -0.4518575 & P39 & 1.7616839 & H64 & 0.2802377 \\
\hline $\mathrm{C} 15$ & 0.4137919 & $\mathrm{O} 40$ & -0.9432346 & H65 & 0.2834756 \\
\hline C16 & -0.3839464 & O41 & -0.8019828 & H66 & 0.2733855 \\
\hline C17 & 0.2415364 & $\mathrm{O} 42$ & -0.7782755 & H67 & 0.2800620 \\
\hline $\mathrm{C} 18$ & -0.2352215 & H43 & 0.2695002 & H68 & 0.2740097 \\
\hline N19 & -0.6074982 & H44 & 0.2768180 & H69 & 0.2839072 \\
\hline $\mathrm{C} 20$ & -0.3682742 & $\mathrm{H} 45$ & 0.2799293 & $\mathrm{H} 70$ & 0.4849134 \\
\hline $\mathrm{C} 21$ & -0.3656204 & H46 & 0.2882830 & H71 & 0.4837532 \\
\hline $\mathrm{C} 22$ & -0.2252762 & $\mathrm{H} 47$ & 0.2714893 & $\mathrm{H} 72$ & 0.4844964 \\
\hline $\mathrm{C} 23$ & -0.3914421 & H48 & 0.2882618 & H73 & 0.4839059 \\
\hline N24 & -0.6253853 & H49 & 0.2808502 & H74 & 0.4845003 \\
\hline $\mathrm{C} 25$ & 0.2672377 & H50 & 0.1894533 & H75 & 0.4844648 \\
\hline
\end{tabular}




\section{Table 7}

Interaction and binding energies between the inhibitor molecules (TPP) and Fe (100) surface.

\begin{tabular}{llc}
\hline Systems & $\mathrm{E}_{\text {Interaction }}\left(\mathrm{kJ} \mathrm{mol}^{-1}\right.$ & $\mathrm{E}_{\text {binding }}\left(\mathrm{kJ} \mathrm{mol}^{-1}\right)$ \\
\hline $\mathrm{Fe}+$ Inhibitor & $-1071,181$ & 1071,181 \\
\hline
\end{tabular}




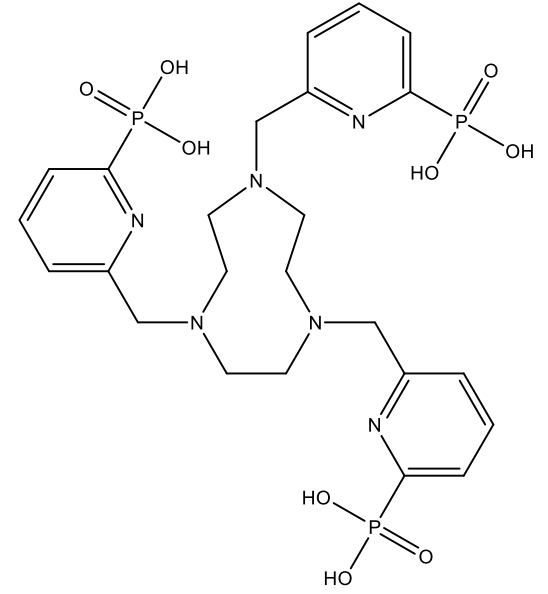

Figure 1. The chemical structure of the inhibitor TPP 


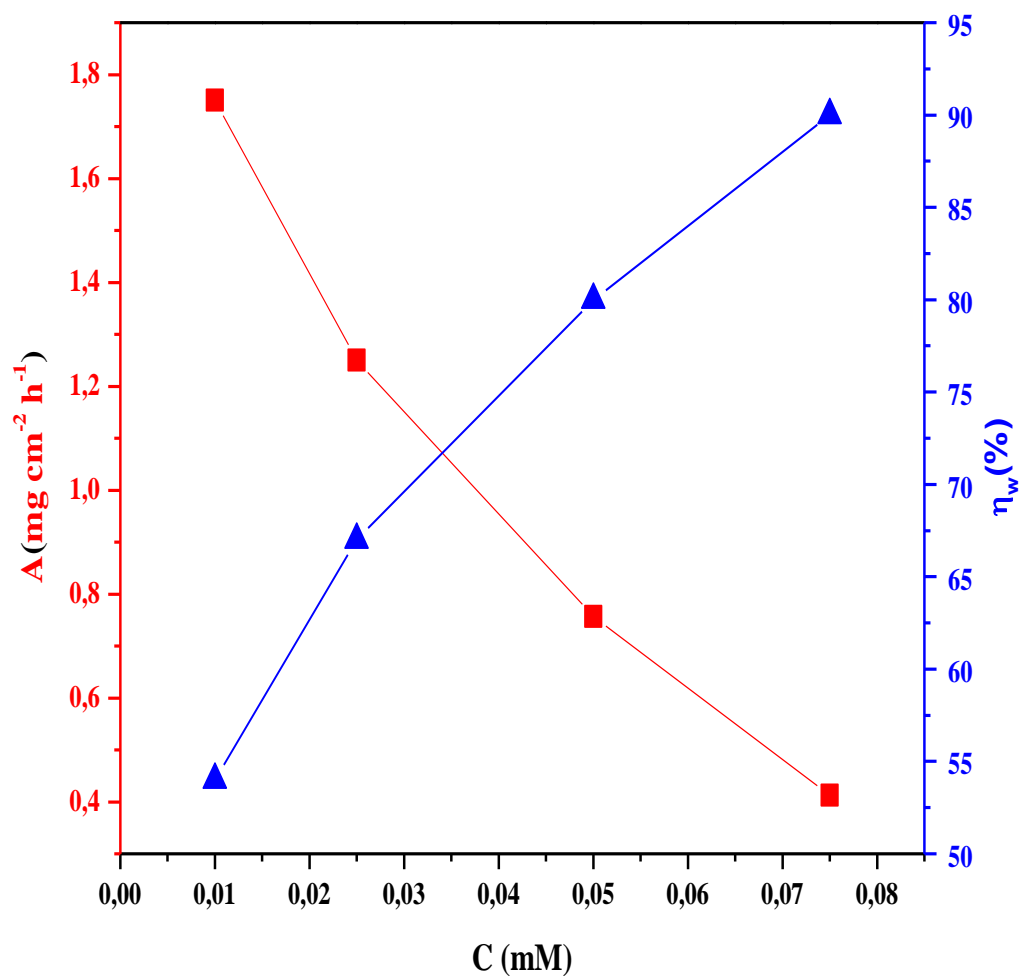

Figure 2. Variation of the corrosion rate $A(\square)$ and the inhibition efficiency $\eta_{w}(\Delta)$ with various concentration of inhibitor (TPP). 


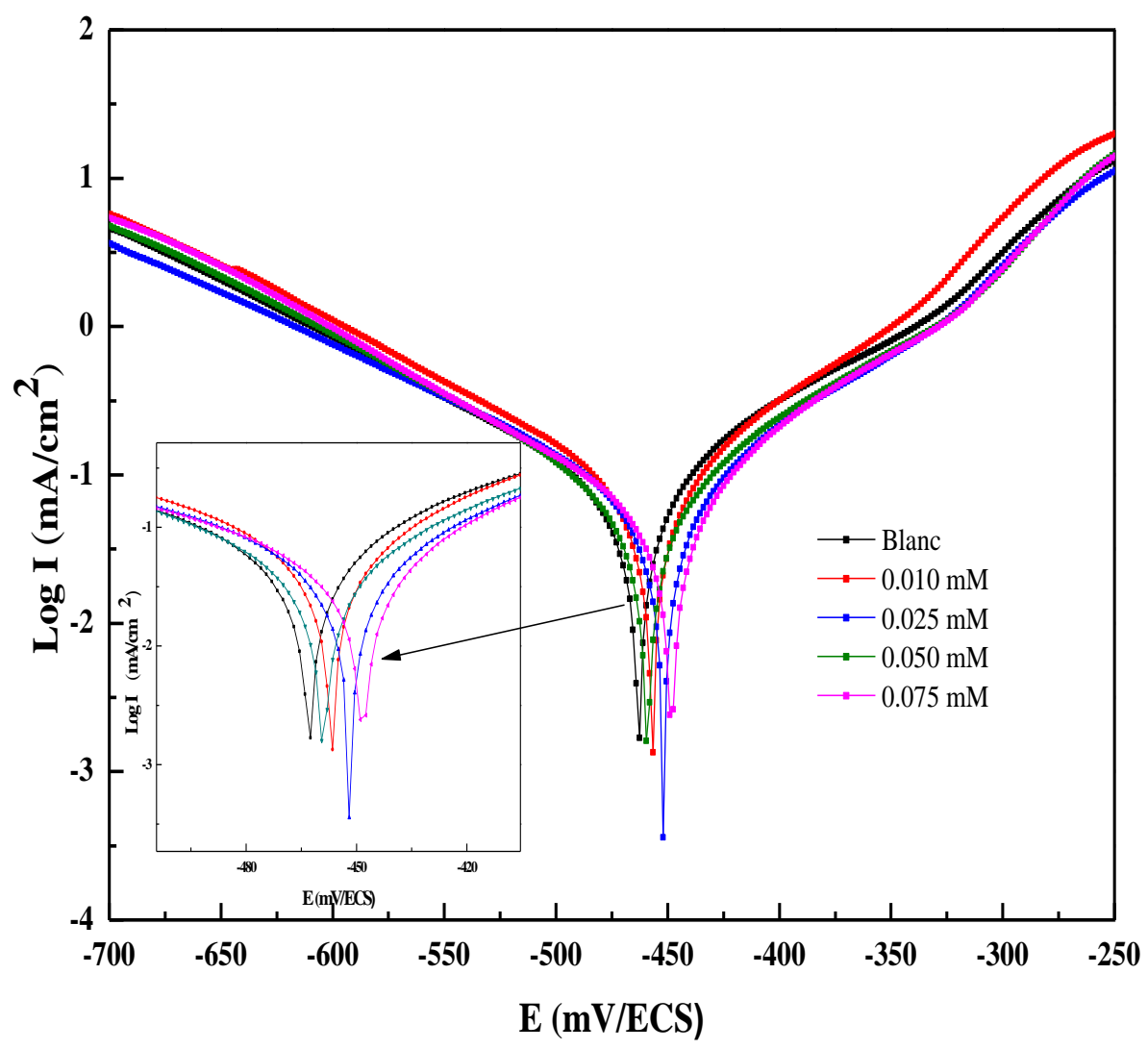

Figure 3. Tafel polarization curves for the corrosion of mild steel XC48 in $1 \mathrm{M} \mathrm{HCl}$ with and without various concentrations of the inhibitor at $25^{\circ} \mathrm{C}$. 


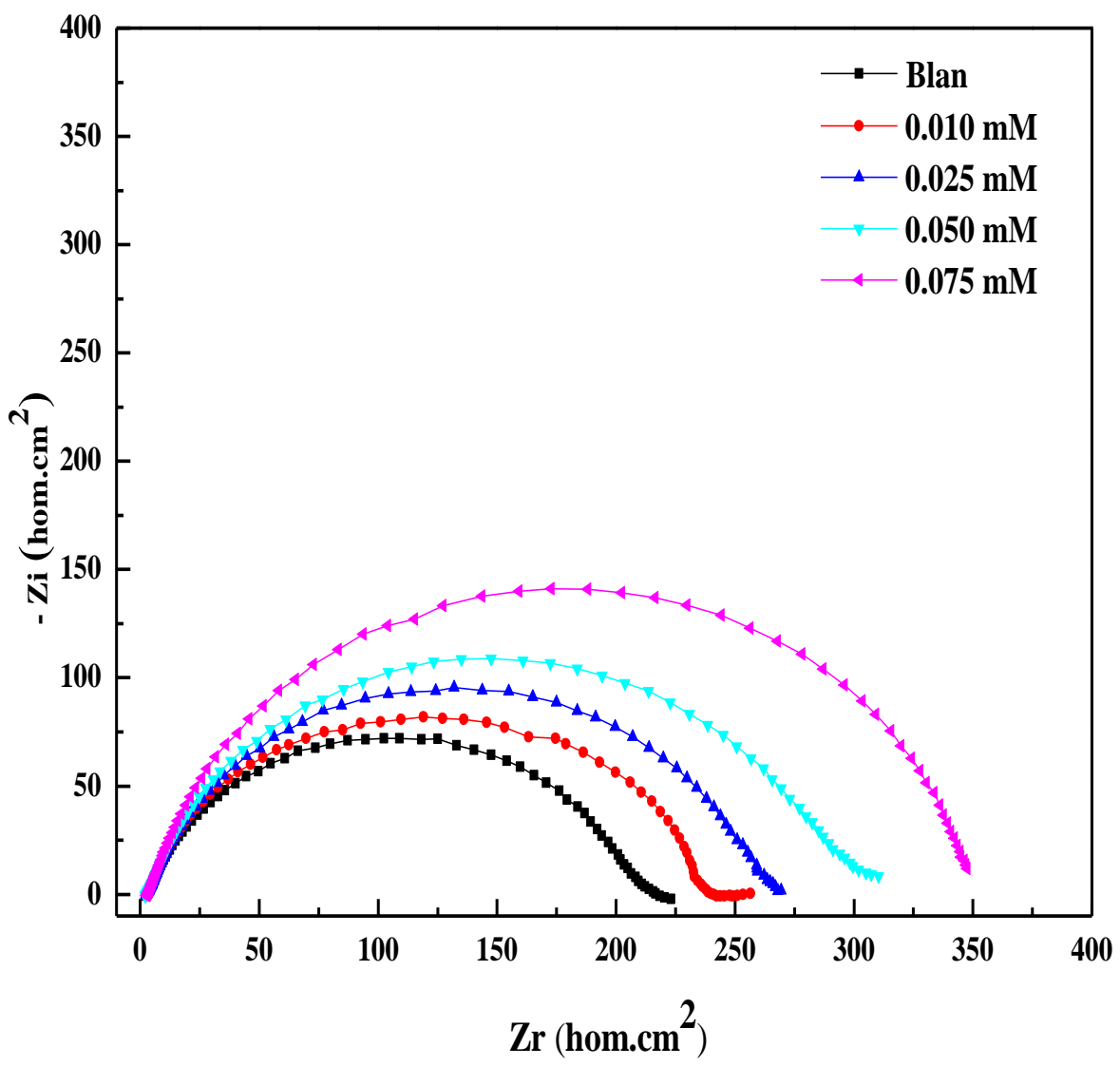

Figure 4. Nyquist plots for the mild steel $\mathrm{XC} 48$ in $1 \mathrm{M} \mathrm{HCl}$ solution without and with different concentrations of the inhibitor (TPP). 

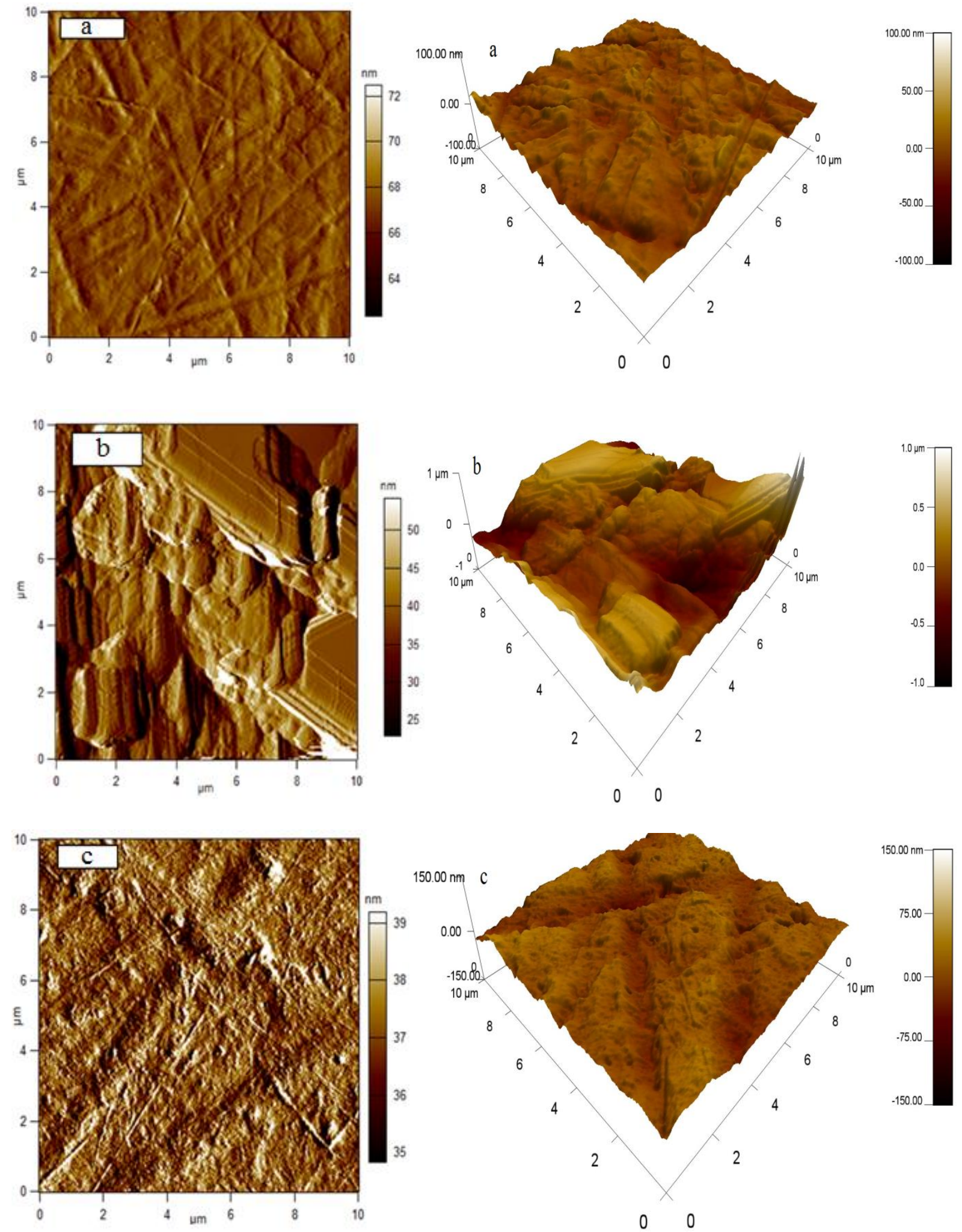

Figure 5. AFM images 2D (on the Left) and 3D (on the Right), mild steel surface ; (XC48) polished mild steel, mild steel in $1 \mathrm{M} \mathrm{HCl}$, mild steel after immersion in $1 \mathrm{M} \mathrm{HCl}$ in presence of $0.075 \mathrm{~m} \mathrm{M}$ of inhibitor(TPP). 


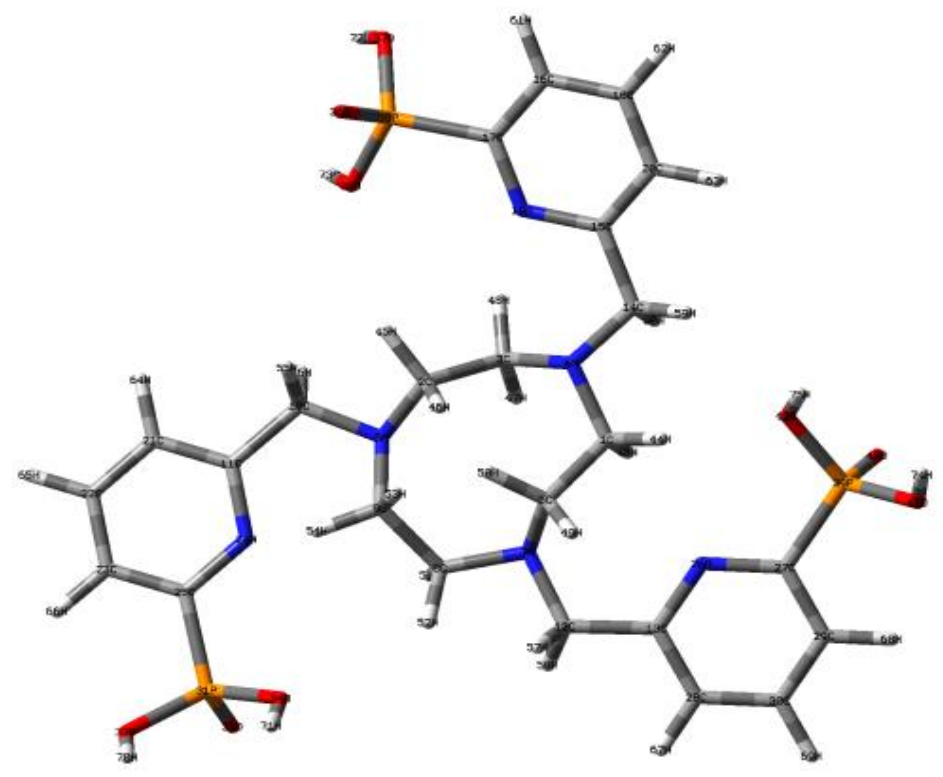

Figure 6. Optimized molecular structure of inhibitor TPP. 


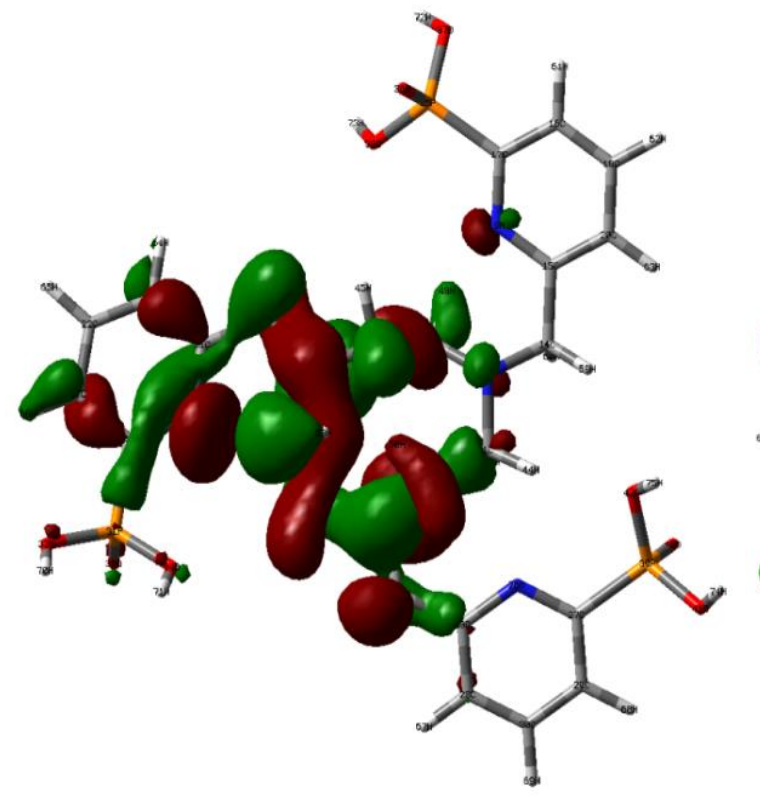

HOMO

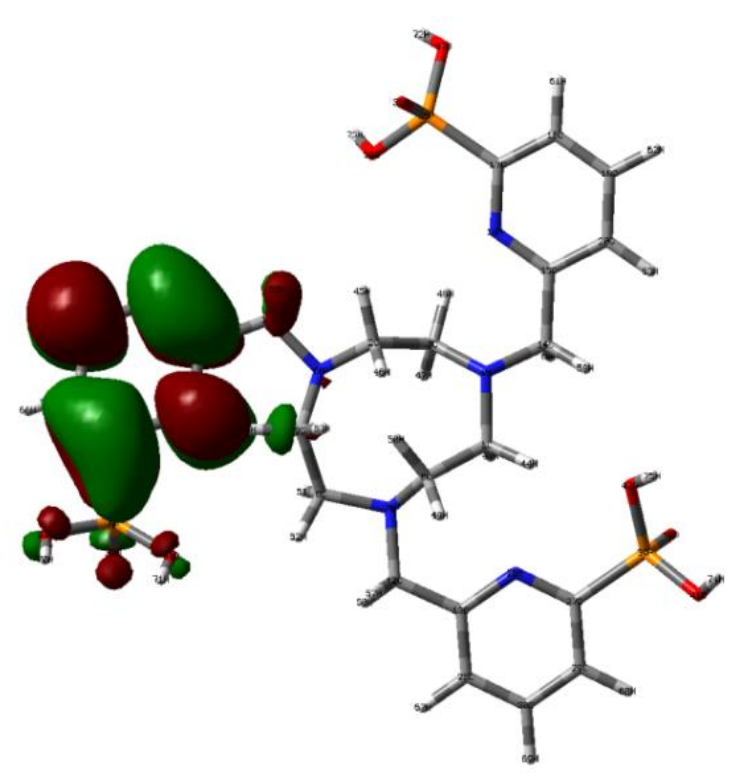

LUMO

Figure 7. The frontier molecular orbital density distributions for inhibitor (TPP). 


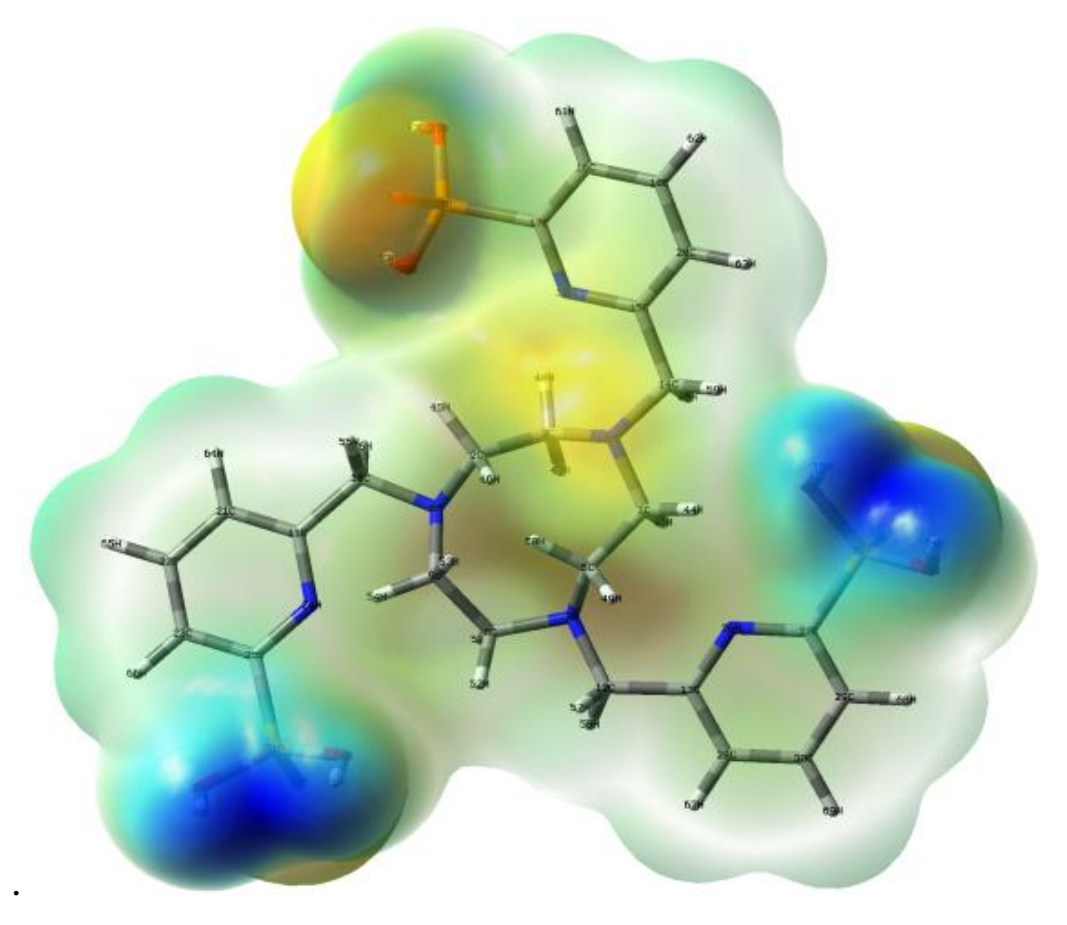

Figure 8. Molecular electrostatic potential of inhibitor (TPP). 

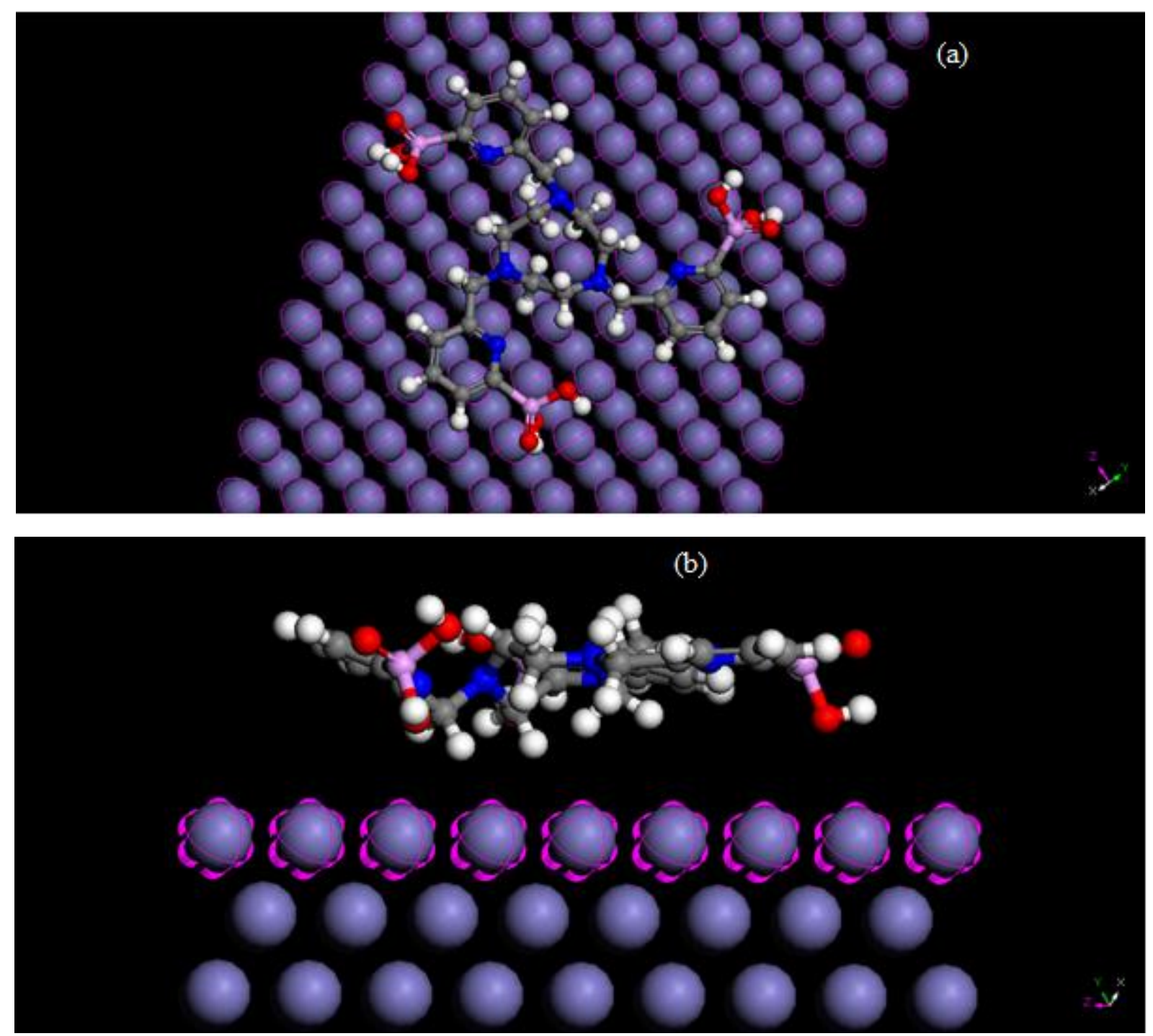

Figure 9. Equilibrium configuration of the adsorbed molecule on the Fe (110) surface vacuum slab: (a) top view, (b): side view. 


\section{Highlights:}

- New organic inhibitor (1,4,7-tris[hydrogen (6-methylpyridin-2-yl) phosphonate]-1,4,7triazacyclononane) (TPP) act as an excellent inhibitor for mild steel in $1 \mathrm{M} \mathrm{HCl}$ solution.

- The corrosion inhibition efficiency of TPP is $90 \%$ at $0.075 \mathrm{mM}$ (obtained from Gravimetric for $40 \mathrm{~h}$ ) and increases with different concentration and immersion time.

- Theoretical calculations provide favorable support for the experimental data. 